\title{
Recalcamento na Dúvida Metódica: Moções Inconscientes e seus Respectivos Atenuadores nas Meditações de Descartes
}

\author{
Repression in Methodical Doubt: Unconscious Motions and their \\ Respective Attenuators in the Methodical Doubt of Descartes
}

\author{
Felipe Cordeiro, 1 Alberto Luiz Rodrigues Timo,2 Marcus Vinicius Silva³
}

\begin{abstract}
Resumo
O objetivo do presente artigo é analisar o conteúdo das meditações, presentes no Discurso sobre o Método (1637) e Meditaçoes sobre a Filosofia Primeira (1641), de Renée Descartes, a partir das noções estabelecidas pelo Psicanalista Jean Laplanche sobre Revoluções Copernicanas e recaídas Ptolomaicas. Estendendo o designativo Revolução Copernicana, que Laplanche concede à Psicanálise, em específico, à descoberta de um inconsciente no qual residem disposições profundamente sexuais e de origem alteritária, pretende-se a utilização dessa noção para além do texto freudiano, no qual a teorização de Laplanche está prioritariamente concentrada. Uma vez requalificada, propõe-se a partir dessa perspectiva expor as proximidades do percurso de Descartes em suas meditações e a situação analítica. Esse exercício inclui-se na experiência extramuros, na qual a unidade teórica psicanalítica é colocada em movimento, diante de um objeto que lhe é exterior, renovando a sua vocação revolucionária copernicana fundamental.
\end{abstract}

Palavras-chave: René Descartes, 1596-1650; Jean Laplanche, 1924-2012. Psicanálise.

\begin{abstract}
The purpose of this article is to analyze the content of meditations present in Discourse on Method (1637) and Meditations on First Philosophy (1641), both of René Descartes' authorship, based on the notions established by psychoanalyst Jean Laplanche about Copernican Revolutions and Ptolemaic relapses. Extending the Copernican Revolutions designation - which Laplanche grants specifically to Psychoanalysis - to the discovery of an unconscious where there are deeply sexual dispositions with alteritarian origins, the intention is to use this notion beyond the Freudian text, in which Laplanche's theories are mainly focused. Once this new meaning has been assigned, we proposed to expose the similarities between Descartes' meditations and the analytical situation. This exercise includes an experience "beyond
\end{abstract}

\footnotetext{
${ }^{1}$ Universidade Federal de Minas Gerais, Belo Horizonte, Brasil. Contato: felipepsi@live.com.

${ }^{2}$ Universidade Federal de Minas Gerais, Belo Horizonte, Brasil. Contato: alberto_timo@hotmail.com.

${ }^{3}$ Universidade Federal de Minas Gerais, Belo Horizonte, Brasil. Contato: marcusviniciusnsilva@gmail.com.
} 
the walls", where the psychoanalytic practice is put in motion before an external object, renewing its fundamental Copernican revolutionary vocation.

Keywords: René Descartes, 1596-1650; Laplanche, Jean; 1924-2012. Psychoanalysis. 


\section{Introdução}

As contribuições de Descartes para o pensamento moderno são múltiplas, passando pelo que hoje denominamos Matemática, Medicina e Física, sendo reconhecidas sobretudo por sua significativa participação no processo da Revolução Científica. No âmbito da Filosofia, Descartes é reputado como o primeiro pensador moderno, predecessor decisivo e inaugurador de uma série de propostas filosóficas ainda hoje retomadas, como o racionalismo, fundacionismo e ceticismo. Uma das suas principais contribuições para o desenvolvimento do pensamento ocidental é a dúvida metódica, presente nas meditações contidas no Discurso sobre o Método (1637) e nas Meditações da Filosofia Primeira (1641).

Nessas duas obras, o filósofo propõe-se a reorganizar seus pensamentos tendo como premissa o critério de não assumir como verdadeiro nada que seja incerto, reavaliando um grande grupo de crenças cuja verdade é consensualmente admitida. Tal procedimento, conforme expresso nas duas obras, impactara grande afetação sobre o filósofo quando ele constou ter suspendido uma série de crenças fundamentais. Situação da qual se desembaraçou quando o recurso ao Cogito permitiu resgatar e provar a verdade das opiniões anteriormente rechaçadas.

Nesse movimento reflexivo de Descartes, podemos identificar duas disposições: uma revolucionária, que faz parte do legado que o levou a ser qualificado como o fundador da Filosofia Moderna, e outra, mais conservativa, para as quais se direcionam a maioria das críticas e que não legou contribuições tão amplas para o pensamento ocidental. Apropriando-nos da conceituação estabelecida pelo psicanalista francês Jean Laplanche, podemos designar seu método, predecessor do ceticismo científico, como Copernicano e as suas provas da imortalidade da alma, da existência de Deus e do fundo de verdade de nossas crenças e impressões como Ptolomaicas.

Expandindo a designação de Laplanche à incursão de Descartes, podemos, por meio dos recursos teóricos que nos concede a Psicanálise, entrever o jogo de forças entre uma centração e desligamento, associado ao Id, evocado por uma situação de incerteza e ceticismo. Podemos ainda constatar os arranjos presentes no desenvolvimento do Cogito e o consequente resgate de certas crenças, que restabeleceram a ilusória constatação de autodomínio do eu, impondo termo ao jogo de forças aberto pelas meditações.

\section{Psicanálise e Filosofia}

Apesar de o campo psicanalítico se utilizar amplamente da Filosofia como instrumento teórico, são reduzidos os estudos da Psicanálise sobre obras filosóficas. Tal situação decorre das características da escrita filosófica, marcada por um grande grau de racionalização, por força das exigências formais e lógicas às quais se submete. Assim, a produção filosófica é sujeita em sua concepção a um exigente crivo racionalcrítico, distanciando o conteúdo latente que subjaz ao texto da expressão escrita, impondo dificuldades, na maioria das vezes intransponíveis, à investigação psicanalítica que ancora sua investigação nas dissonâncias e aparentes lacunas do discurso e comportamento. 
No âmbito da Filosofia, porém, são conhecidas circunstâncias nas quais a apreensão do objeto estudado, no mais das vezes abstrato, permite a manifestação de determinados afetos e expressões. Figuram como exemplares nesse sentido as meditações de Descartes, presente nos Discursos e as Meditações.

Em termos gerais, a viabilidade do procedimento interpretativo-analítico para as obras filosóficas reside na presença de objetos cujo estudo exige ou permite a manifestação dos fenômenos negativos do sentido (Miller, 1987, p. 35), cuja inteligibilidade e importância para a compreensão da natureza humana fora resgatada pela Psicanálise desde suas origens, em contraste na ocasião, justamente, com o discurso predominante no campo filosófico.

\section{As meditações na experiência extramuros}

A incursão psicanalítica sobre uma obra filosófica poderia, a princípio, ser apropriadamente classificada como um estudo de Psicanálise Aplicada, porém, tendo em vista o que se pode depreender a partir do termo "aplicado".

"Aplicação" suporia que, a partir de um domínio privilegiado, que, com efeito, é o tratamento, uma metodologia e uma teoria seriam abstraídas, para, em seguida, serem transferidas, sem mais, como numa engenharia - para outro domínio, assim como a ciência aplicada de um engenheiro, para construir uma ponte, nada mais é do que uma engenhosa derivação a partir dos conceitos fundamentais da física ou $\mathrm{da}$ mecânica. (Laplanche, 1992, p. 11)
Assim, tal designação não expressa adequadamente as características metodológicas de uma incursão extramuros e as premissas metodológicas que norteiam a presente pesquisa cuja oportunidade para definir mais detalhadamente encontramos no prosseguimento do presente tópico.

Desde suas origens, a Psicanálise apresentara uma flexibilidade de seus conceitos fundamentais em função de sua experiência, que para Laplanche (1992, p. 16) abrangia além, do campo extramuros, os domínios da teoria, história e clínica. São decisivas nos rumos da obra de Freud as incursões sobre a produção artística e a condição dos seus criadores certa genealogia da moral e do monoteísmo, demonstrando interesse particular para as experiências e indivíduos extrínsecos.

É exemplar, nesse sentido, a incursão de Freud sobre os casos patológicos, extrínsecos ao corpo diagnóstico e normatizador de seu tempo, postura que conta entre seus resultados os Estudos sobre Histeria (Freud \& Breuer, 1893-5/1976). Em vez de impor a essas condições o rótulo de extravio da lei natural, o fundador da Psicanálise não só reconheceu a legitimidade desses fenômenos, incluindo-os no saber de seu tempo, como pode retificar e expor novas proposições acerca da natureza humana, para o qual o Projeto para uma Psicologia Cientifica figura como exemplo (Freud, 1950/1996). Essas proposições estiveram parcialmente abertas a retificação, na medida em que outras pesquisas e o tratamento de outras condições incluíram-se na experiência psicanalítica, como pode ser observado explicitamente em Além do Princípio do Prazer (1920/2006). 
Ao propor os quatro lugares onde se realiza a experiência psicanalítica, Laplanche (1992, pp. 10-11) define o ser humano, como teorizante da própria experiência e de si, como objeto da Psicanálise. Para o autor, o ser humano encontra-se desde seu início na posição forçada de hermeneuta (Tarelho, 2012, p. 103), sendo o recalque coincidente com a tradução do excesso pulsional. A instância do eu é sempre forçada ao trabalho pelo $i d$, originário do resto da primeira tradução que caracteriza o recalque originário (Laplanche, 1998, p. 90). É nesse jogo, entre a capacidade tradutiva do eu e o sexual intraduzível, que se situa a tensão entre tendências copernicanas e ptolomaicas no psiquismo.

A experiência exportada ou extramuros, enquanto um dos quatro lugares da experiência psicanalítica, suscita o descentramento desse campo, fazendo orbitar seus conceitos em torno de objetos externos, não pertencentes a um corpo teórico centrado em si. A estrangeiridade do objeto extramuros proporciona a abertura da teoria psicanalítica, não necessariamente levando a sua reconfiguração. As sucessivas incursões extramuros permitem que o campo psicanalítico orbite em torno de objetos de apreciação externos, combatendo uma tendência Ptolomaica, na qual são acionados diversos epiciclos, hipóteses ad hoc, para conformar o domínio exportado às predições de um modelo teórico autocentrado.

Em que medida é possível dizer que as meditações de Descartes são objetos possíveis da experiência extramuros? $\mathrm{Na}$ medida em que as duas obras, as Meditações e Discurso sobre o Método, são teorizações da experiência humana que embasaram um modelo influente de tradução dessa condição, favorecedor de mecanismos de descentramento e autocentração.

A Filosofia do século XVII concedeu especial atenção para a profilaxia do engano, sendo Descartes um dos inauguradores dessa corrente, propondo-se construir uma nova ciência e, com o mesmo gesto, reduzindo a loucura ao silêncio (Teixeira \& Santiago, 2017). Foucault localiza nas Meditações de Descartes a exclusão da experiência da loucura do campo sujeito, anteriormente à experimentação da dúvida em sua reflexão (Nascimento, 2017, p. 136).

Tais considerações de Foucault foram objeto de crítica por Derrida, que aponta a presença de duas modalidades diferentes da dúvida nas Meditações de Descartes, sendo apenas a primeira, a dúvida natural ingênua, abordada por Foucault. Derrida acrescenta que a figura do Gênio Maligno introduz outra forma de dúvida da qual Descartes não afastara o horizonte da loucura (Birman, 2010, pp. 10-18).

A observação de Foucault, presente em sua História da Loucura, indica a proscrição das experiências patológicas ou da loucura, cujo saber esteve em causa para o campo Psicanalítico em diversos momentos de seu desenvolvimento. Assim, fora na trilha dos fenômenos negativos do sentido da loucura histérica, na qual Freud aproximou-se do fundamento alteritário da experiência humana, Descartes distanciou-se parcialmente do descaminho que encaminha descoberta do descentramento.

Já a crítica de Derrida aponta para a figura do Gênio Perverso como reatualização da possibilidade da loucura, restabelecendo o corolário do descentramento. Ambas as observações apontam para a importância decisiva 
de figuras alteritárias no desenvolvimento das meditações, seja como a figura do louco que não se pode ser ou de um Gênio maligno, estrangeiro que é posteriormente incorporado quando substituído pelo Deus perfeito como objeto dessa reflexão.

O movimento do Cogito de Descartes apresenta-se como um similar metódico, localizado em um contexto anterior à Psicanálise, do movimento presente e buscado na experiência analítica, de aberturas, com a destituição de referências antigas, para a incorporação do estrangeiro. Podemos aprofundar-nos na análise desse jogo de forças presente nas Meditações transpondo para Descartes a proposição de Laplanche de que "Freud é para si mesmo seu próprio Copérnico, mas também seu próprio Ptolomeu" (Laplanche, 1993, p. 8). Para tanto, é necessário requalificar essa formulação apresentando seu contexto e construção.

\section{A Revolução Copernicana em Freud e seu contexto}

Pode-se dizer que as Revoluções Científicas consistiram em um grande sucesso investigativo, técnico e ideológico. Para os primeiros, o grande avanço das tecnologias, econômico e das condições gerais de vida da população mundial ainda presta um contundente depoimento. Para o último, é demonstrativa a persistência da ideia bastante otimista que sustenta haver certa neutralidade e potencial ilimitado de produção de progresso das ciências modernas, assim como a noção de que as chamadas Ciências Duras apresentam uma configuração, se não ideal, ótima de um determinado saber quanto a suas potencialidades, metodologia e organização.

O aspecto ideológico que compõe o sucesso das Revoluções Científicas está intimamente ligado à História das Ciências do século XIX e seus predecessores, cujos herdeiros passaram a conviver com uma contrapartida apenas na metade do século XX. ${ }^{4}$ Essa nova perspectiva sobre o desenvolvimento e expansão das Ciências ainda é persistentemente secundarizada por uma epistemologia predominante das Ciências, mesmo tendo ganhado terreno nos campos da Historiografia e Sociologia, o seu nascedouro.

O aparecimento de uma História das Ciências no âmbito das Revoluções Científicas remonta aos séculos XVI e XVII, no qual se observa pela primeira vez um número crescente de escritos históricos nas Ciências (Debus, 2004, p. 15). No referido período, estava refletido nos escritos dos então historiadores contemporâneos o movimento para a reforma da religião e da ciência, que em seus posicionamentos se utilizavam de uma história para sustentar suas convicções (Debus, 2004, p. 15).

Exemplar nesse sentido é a questão evocada por Debus (2004) sobre as controvérsias mantidas entre Galenistas e Paracelcistas, no âmbito da História da Medicina e da Química, na qual se insere o conde R. Bostocke. Em suma, a Medicina paracelcista, da qual Bostocke era partidário, era antigalênica e antiaristotélica (Debus, 2004, p. 16). Bostocke, particularmente,

\footnotetext{
${ }^{4}$ Referimo-nos à perspectiva inaugurada por Thomas Kuhn (1922-1996).
} 
rejeitava as consideradas falsas filosofias de Aristóteles e Galeno, ambos pagãos, sendo que os que se engajam na busca da verdade deveriam consultar o livro da natureza e a Sagrada Escritura (Bíblia). Esse autor dedicara algo próximo da metade de sua obra The difference between the auncient Phisicke... and the later Physicke (1585) à História da Medicina e da Química. A versão histórica presente na referida obra apontava que $\mathrm{o}$ conhecimento pleno das substâncias, seus efeitos e suas misturas fora concedido a Adão, podendo ser recuperado a partir do Antigo Testamento, estava também parcialmente preservado nos escritos pré-socráticos do qual Aristóteles teria se desviado. Posteriormente, apenas uma minoria de estudiosos bizantinos e islâmicos preservara esses conhecimentos. Dessa forma, Paracelso não fora inovador e, de modo semelhante a Copérnico, havia reinstalado o verdadeiro conhecimento antigo. (Debus, 2004, p. 18)

É interessante a forma pela qual o triunfo dos mecanicistas conferiu à História das Ciências como a conhecemos uma ênfase nas Ciências Físicas e Astronomia (Debus, 2004, p. 18), deixando parcialmente ilegível a História da Medicina que aqui mencionamos. É exemplar para nesse ponto a forma como difere a História da Medicina de Friend (mecanicista e discípulo de Newton) quando comparada às anteriores Paracelcistas e Galenistas da Renascença. A primeira critica a visão religiosa e mística dos segundos, agora considerada estranha às premissas científicas e interdita qualquer crédito

\footnotetext{
${ }^{5}$ São numerosos os projetos de qualificação dos saberes não científicos, entre eles: Lewin, K. (1931). The conflict between Aristotelian and Galileian modes of thought in contemporary Psychology. Journal of Gen. Psychol., 5, 141-177; Skinner, B. F. O Mito da Liberdade (pp. 9-24). Summus editorial; e Payen, P.
}

que possa ser dado a Paracelso em favor dos médicos e químicos árabes e bizantinos (Debus, 2004, p. 20).

Podemos observar como essa disposição adentrou no século XX e ainda é retomado no contexto contemporâneo. Ainda se observam histórias de precedentes em trabalhos científicos, bem como apologias de determinados pontos de vistas, embasados ou semiembasados por uma genealogia de seus predecessores científicos. Porém, é do nosso interesse atentar para a maneira pela qual esse recurso se manifesta nas chamadas novas ciências, nos campos fronteiriços nos quais se almeja alcançar um rigor e potencial de desenvolvimento semelhante ao das chamadas Ciências Duras.

O triunfo mecanicista, como dissemos, conservou na história das Revoluções Científicas uma ênfase na Física e Astronomia algo que está diretamente ligado aos projetos de Fundação de novas ciências que se observa historicamente, sobretudo a partir da segunda metade do século XIX. A inspiração desses novos projetos é, em sua maioria, predominantemente Copernicana e Newtoniana, de modo que lidamos com propostas e prenúncios de revoluções copernicanas na Filosofia, Educação, Direito, bem como tentativas de adequação à Matemática Vetorial e quantificação da mecânica newtoniana ${ }^{5}$.

Não é possível deixar de mencionar nesse desenvolvimento a figura de Kant, cujo projeto de exportação da Revolução Copernicana ainda é influente. Como observa Laplanche (1993, p. 7),

(2011). A constituição da História como ciência no século XIX e seus modelos antigos: fim de uma ilusão ou futuro de uma herança?. História da historiografia, 6 , 103-122. Recuperado de file://C:/Users/user/Downloads/250-930-1PB.pdf 
a tentativa de Kant de fazer o observador girar e deixar as estrelas em repouso no que concerne à metafísica. Contudo, prossegue, há nesse movimento um recentramento radical, uma vez que seu projeto pretensamente copernicano faz regular o objeto a partir de nossa Razão.

$$
\text { Contaminado pelo imaginário }
$$

oitocentista pós-kantiano sobre as Revoluções Científicas, que reconhece uma especificidade e desdobramentos sem precedentes nesses eventos, Freud compara a descoberta da Psicanálise com as de Copérnico e Darwin, agrupando-as no conjunto dos grandes golpes narcísicos que a Ciência infligira à humanidade, visando ressaltar a radicalidade de sua criação.

A terceira e mais sensível ofensa que a megalomania humana sofreu partiu da pesquisa psicológica da época atual que procura provar ao eu que ele não é senhor nem mesmo de sua própria casa, devendo, porém, contentar-se com escassas informações acerca do inconsciente em sua vida anímica. (Freud, 1917/1990, p. 32)

Afastando-se de uma modéstia prudencial, Freud qualifica a evidenciação do inconsciente como o golpe mais profundo, em função de seu caráter interno, entre aqueles que a tradição científica, enquanto modalidade privilegiada de obtenção do conhecimento, impetrara no homem em raros e célebres casos. O fundador da Psicanálise estabeleceu como o primeiro golpe narcísico infligido ao que qualificara como "megalomania humana", a derrocada do Geocentrismo Ptolomaico empreendida pelas teorias heliocêntricas de
Nicolau Copérnico. O segundo fora infligido na ocasião da elaboração, reputada ao naturalista Charles Darwin, da evolução das espécies, que insere a humanidade no continuísmo entre as espécies, derrubando a convicção humana de uma origem completamente distinta dos animais. $\mathrm{O}$ terceiro golpe mencionado por Freud é a Psicanálise, para a qual, do mesmo modo que para os golpes antecedentes, não deixa de reconhecer predecessores avant la lettre. A descoberta do inconsciente destituiu o gênero humano da soberania sobre os seus próprios pensamentos, comportamentos e motivações.

Esse parecer revela-se, quando pensado em seu contexto, como laudatório à Psicanálise, já que a inclui em um seleto e célebre grupo de descobertas científicas. Além disso, é ilustrativo sobre a sua pretensa radicalidade ao incluí-la em um grupo de teorias amplamente identificadas como opositoras de influentes concepções vigentes na ocasião de sua gênese e que, posteriormente, tornaram-se hegemônicas. Há nesse elogio a expressão de um prognóstico, que na ocasião de sua publicação já se realizara parcialmente: o impacto irreversível das descobertas da Psicanálise sobre a História do Pensamento e visão de mundo do Homem, ou seja, o potencial dessa ciência da alma de requalificar a forma de a humanidade ver o mundo e seus critérios, tal como o heliocentrismo e a evolução. Freud reconhece a similitude entre as veementes críticas e combates direcionados à Psicanálise e os primeiros obstáculos enfrentados por essas grandes teorias, em função de sua natureza profundamente radical; a introdução da Psicanálise nesse seleto grupo é mobilizada para explicar as resistências ainda verificadas em 
relação a esse campo (Freud, 1917/1990, pp. 3031).

Freud, ao remeter-se ao darwinismo e copernicanismo, não dista muito da ideologia cientificista de seu tempo, guardando a ressalva de que seu uso tenha sido mais laudatório e persuasivo do que organizador de suas teorias. Contudo, figura como importante verificar o que intenta dizer esse parecer do fundador da Psicanálise e com quais conceitos e construções desse campo mais profundamente se articula, independentemente do quão inadequada seja a ficção histórica na qual se assente, tendo em vista o valor epistemológico que apresenta.

Assim, concentramo-nos no fato de que Freud, ao verter essa explicação sobre as resistências à Psicanálise (Freud, 1917/1990, p. 32), acaba por evadir as fronteiras do campo psicológico, levantando uma designação de interesse epistemológico. Esse menciona os golpes ao amor-próprio humano impetrados pela investigação científica, pautada no princípio de realidade, na derrocada de convicções ilusórias e egossintônicas, algo que podemos desde então designar como golpe narcísico.

A explicação freudiana concede instrumentos conceituais importantes para se investigar os aspectos psicológicos da investigação racional, em sentido mais amplo, do exame e da concepção de ideias, enfatizando seus desvios. A apreensão da realidade, suposta prioridade de toda investigação, convive com uma série de limitações, sobretudo aquelas decorrentes do potencial finito e falibilidade das faculdades mobilizadas no processo racional. Porém, a defectibilidade do entendimento humano não é decorrente apenas da insuficiência do que podemos chamar de faculdade do Entendimento.
Os desvios da exigência perfeccionista que a tradição Racionalista tem em vista, o da pura e ilimitada Razão, também se relacionam a um polo de exigência extrínseco à atividade racional, o narcisismo.

A monstruosa indiferença da realidade às convicções, esperanças e necessidades mais básicas do gênero humano, sobre sua especificidade, relevância e potencial em face da desproporcional e inapreensível magnitude do universo, levanta, in genere, defesas por parte do investigador, sobretudo quando a realidade tende a cruamente destruir suas crenças mais fundamentais, aquelas que o gênero humano ou o meio de certa cultura concebem como fundamentais à realização da existência. Tais crenças figuram como aspecto essencial das traduções que o sujeito faz de suas experiências, figurando como defesa de si mesmo em relação à alteridade que o funda. A instabilidade do mundo externo demove o sujeito da centralidade de seu mundo, tornando-o mais vulnerável ao ataque de sua alteridade interna que guarda tendências contrárias à vida.

O potencial do emblemático parecer freudiano de possibilitar o estabelecimento de uma metodologia, para a leitura crítica da investigação racional, é explorado por Jean Laplanche na ocasião de sua revisão da própria obra de Freud. Laplanche, ao empreender o retorno - que pode ser melhor entendido como renovação - aos fundamentos da Psicanálise, atribui duas distintas disposições teóricas do fundador da Psicanálise, a partir dos qualificativos copernicano e ptolomaico. 


\section{O retorno ao copernicanismo na revisão de} Jean Laplanche

A exemplo de Jacques Lacan, Laplanche reconhece o potencial impactante das descobertas de Freud e a tendência de sua dissimulação e domesticação, diante da qual se impõe a tarefa que consiste em

[...] restaurar a relha cortante de sua verdade (a descoberta por Freud) - que retoma a práxis original que ele instituiu sob o nome de psicanálise no dever que lhe cabe em nosso mundo - que, por uma crítica assídua, denuncia os desvios e os compromissos que amortecem seu progresso, degradando seu emprego. (Lacan, 1980, p. 45, adaptado)

Laplanche, porém, rejeitara uma série de proposições e consequências da teoria lacaniana decorrentes do retorno a Freud empreendido por Lacan e seus colaboradores, entre os quais contava o próprio Laplanche por certo tempo. Não convém aqui analisarmos detidamente os detalhes dessa cisma intelectual, porém, a título de menção, podemos citar a questão mantida por Laplanche com a frente lacaniana sobre o caráter realista e individual do Inconsciente, defendido pelo primeiro em contraposição à corrente lacaniana que advoga em favor da impessoalidade e estatuto imaginativo-ético dessa instância na realidade (Honda, 2013, p. 52).

Diferentemente da corrente lacaniana, o autor se concentra prioritariamente nos entremeios do percurso de Freud que culminaram na célebre carta 69 a Fleiss, de 21 de setembro de
1897, na qual Freud admite a seu colega de Berlim o abandono do que Laplanche denominou posteriormente como Sedução Restrita. Nessa ocasião, Freud havia reunido na investigação analítica de seus pacientes uma série de cenas primeiras, referentes a uma experiência sexual prematura, na qual a então criança fora passivamente submetida à sexualidade de um adulto, figurando uma situação de abuso. Tais cenas foram descobertas em uma desagradável abundância, a partir da investigação da etiologia da histeria, para a qual esses resultados apontavam uma inverossímil quantidade de pais perversos.

Munido de um reconhecido conhecimento na leitura e interpretação da obra freudiana, que lhe rendera o convite para ser o coordenador editorial da tradução francesa das obras de Freud (Campos, 2012, p. 23), Laplanche se lança na leitura da obra freudiana a partir dos próprios fundamentos que os primeiros textos psicanalíticos estabeleceram, atento aos furos, incoerências e desvios nos quais o fundador da Psicanálise incorrera. Com esse recurso interpretativo, Laplanche visa categoricamente afastar sua leitura de Freud do campo da Hermenêutica, apesar de reconhecer a impossibilidade de definir completamente essa incursão, ele se limita a delimitá-la nos seguintes termos:

Uma história estrutural do pensamento de Freud é talvez possível sob a condição de levar plenamente em conta, no seu próprio método, o pensamento freudiano. Impõe-se como pré-requisito um longo contato junto a uma obra e aos 
seus impasses e aceitar plenamente o tempo de uma análise "redutora". (Laplanche, 1988, p. 32)

Sob essas considerações, a incursão laplanchiana sobre a obra freudiana identifica no percurso que Freud, como mencionamos, interrompera em 1897 a direção do aprofundamento da descoberta da origem, caráter alteritário e sexual do inconsciente. $\mathrm{Na}$ investigação da etiologia das neuroses, concentrada na histeria, Freud extraíra no tratamento psicanalítico uma série de relatos de situações de abuso impetradas geralmente pelos pais, em uma condição de imaturidade sexual dos pacientes, ao que Laplanche denominou posteriormente como sedução infantil (Laplanche, 1988, p. 109).

Como a própria trajetória de Laplanche depõe, a sedução infantil é indicativo do quanto estava Freud na trilha das proposições e desenvolvimentos que posteriormente Laplanche elaborou sobre a Teoria da Sedução Generalizada, apoio e Situação Antropológica Fundamental. O fundador da Psicanálise, porém, ante a radicalidade das possibilidades teóricas que essas cenas de abuso sugeriam, afastou-se parcialmente da pesquisa por uma cena primeva, cedendo espaço para explicações que recorriam a uma origem endógena, biológica e histórica do inconsciente e sexualidade. Contudo, Freud não deixou de haver-se com a descoberta da sedução e origem alteritária do inconsciente, mas esse caminhamento deu-se segundo diversos momentos de abertura e fechamento para essa dimensão fundamental de sua obra.

Assim, segue que o legado de Freud apresenta certa incompletude. Diante da perturbadora radicalidade das conclusões e implicações, muitas delas de ordem pessoal, que a descoberta da sedução infantil indicara, o fundador da Psicanálise abandonou parcialmente essa trilha, privando a Psicanálise do que seria para Laplanche a descoberta mais fundamental e genial, referente à Sedução Generalizada e Situação Antropológica Fundamental. O psicanalista francês debruça-se sobre uma série de prosseguimentos da obra freudiana, na qual se observam recuos em relação à afirmação da origem perversa e alteritária da sexualidade humana, do Inconsciente e da pulsão, como também parciais avanços na direção de sua negação. Com isso, sinteticamente, Laplanche retoma a máxima freudiana, enunciando que “Freud é para si mesmo seu próprio Copérnico, mas também seu próprio Ptolomeu" (Laplanche, 1993, p. 8), explicitando a sua concordância parcial com a radicalidade que Freud atribui para si.

Em Revolução Copernicana Inacabada (1993), Laplanche se concentra em uma exposição sintética de suas teorias, mas em segundo plano resgata o aspecto expansivo e potencial epistemológico ao qual a máxima freudiana alude, sendo por essa razão do maior interesse para a presente pesquisa. $O$ autor identifica a descoberta do Inconsciente e da sedução, conforme mencionado anteriormente, como Revolução Copernicana e as propostas de uma origem endógena, filogenética e as decorrentes domesticações do sexual e da pulsão, tomadas a partir do abandono da sedução, para qual a carta de 1897 constitui um marco, como ptolomaicas. A esse respeito, sinteticamente, Laplanche (1993, p. 8) expressa que 
A revolução astronômica durou aproximadamente dois milênios com, quase desde o início, intuições do verdadeiro, mas também com um extravio inicial. $\mathrm{Na}$ psicanálise tudo se produz, no que tange ao essencial, num único homem. Ao mesmo tempo: a descoberta, muito precocemente afirmada e que é conjuntamente (e, segundo eu, indissociável) a do inconsciente e da sedução - e o extravio, a falsa via adotada cada vez, onde é feito o retorno a uma teoria da auto-centração, e mesmo auto-engendramento.

Essa leitura de Laplanche sobre o percurso de Freud fundamenta a presente pesquisa e tendemos a estender essa dupla disposição, copernicana e ptolomaica, para outros autores, julgando que diante da incerteza brutal imposta pelo superlativo da verdade e a polivocidade de teses parciais que a experiência faz depor, o gênero humano empreende um fechamento egossintônico, narcísico por excelência, visando domesticar o horizonte de incerteza e ambivalência imposto pela realidade às necessidades atreladas à função do Eu. Nesse sentido, consideramos as proposições de Laplanche sobre Freud como paradigmáticas e capazes de conduzir ao reconhecimento de um processo mais amplo.

Diferentemente de Freud, Laplanche não reconhece a revolução darwiniana como revolução produtora de descentramento da experiência humana.

Com efeito, negligenciei provisoriamente o fato de Freud intercalar, entre humilhação copernicana e a humilhação psicanalítica, a ferida infligida no nosso orgulho pelas descobertas evolucionistas e atribuída a "Charles Darwin e seus precursores". O homem se crê de origem divina, estrangeiro ao mundo animal, aprende da ciência que "é ele próprio originário da série animal". Ora, esse lugar concedido ao evolucionismo e à humilhação dita biológica, entre as excentrações propostas por Copérnico e por Freud parece-nos ambíguo e perigoso. (Laplanche, 1992, p. 16)

A partir do que foi estabelecido anteriormente, é possível reconhecer que os golpes narcísicos impetrados pela ciência eleitos por Freud estão sugestivamente relacionados com sua formação científica. Freud aparenta ter logrado uma humilhação à humanidade possibilitada pela aplicação da metodologia científica na terceira grande frente do conhecimento, a das ciências da alma. A postura de Laplanche, por outro lado, relaciona-se com a sua já mencionada concepção de desvio biologizante, que para o autor desviara Freud da radicalidade presente na descoberta do inconsciente e seus desdobramentos.

Cabe aqui observar que não estão em jogo as propostas biológicas de Freud, e sim a revolução proporcionada pelo evolucionismo, algo muito mais difícil de ser rejeitado enquanto descentradora da experiência humana, ainda que em Freud cumpra uma função oposta. Essa dissonância na concepção de Laplanche apontaria para o aspecto ptolomaico de seu modelo?

Essa observação permite-nos entrever a dimensão conservativa e necessária do narcisismo 
na atividade teórica, expressa na atribuição de um sentido ao evolucionismo que conflita com a radicalidade de sua descoberta. Laplanche demonstra em outras obras compreender pertinentemente $\mathrm{o}$ aspecto normativo $\mathrm{e}$ mitológico com o qual Freud (1997, p. 8) introduz considerações biológicas em seu modelo teórico e distingue-as de contribuições biológicas legitimas. Contudo, ao propor a Psicanálise como revolução inacabada, insere a Biologia como recentramento, fazendo coincidir a teleologia biológica de Freud com a descoberta darwiniana. De fato, a radicalidade da descoberta darwiniana não pode ser incorporada ao modelo psicanalítico, sendo válido o contrário. Essa incompatibilidade entre as duas grandes revoluções é demonstrativa de como os sucessivos descentramentos da condição humana exigem fechamento para funcionarem como modelo teórico transmissível. Assim, tal como o humano, esses modelos necessitam de um fechamento e falso centramento para sobreviverem, estando sujeitos à ação de seu conteúdo disruptivo interno, sempre capaz de proporcionar sua reabertura que coloca em jogo sua sobrevivência e renovação.

Esse jogo de forças pode ser observado nas meditações de Descartes, movimento que reúne as características de um sistema subjetivo de traduções e de construto teórico fundante da experiência moderna.

\section{Copernicanismo e recaídas ptolomaicas nas meditações de Descartes}

Na ramificação filosófica de sua obra, Descartes propõe uma tentativa de expansão do grau de fundamentação e certeza presente no campo das Matemáticas para a Filosofia, ciência na qual, apesar da grande reputação atribuída a seus temas, não se encontrava nenhuma matéria cuja decisão estivesse seguramente estabelecida e fosse consensualmente acatada. Diante desse dissenso mantido também entre os homens ilustres, Cartesius opta por não se decidir por nenhum desses, "reputando praticamente como falso tudo quanto era somente verossímil" (Descartes 1637/1981, p. 36), ou seja, não assumindo como verdadeiras proposições que, apesar de consistentes, não poderiam ter sua veracidade comprovada. Tal projeto implicava sobre as ciências e os temas da vida, na medida em que, para o pensador, esses dois âmbitos retiravam suas bases da Filosofia. Essa proposição inicial, que delimita o propósito das Meditaçoes, indica o procedimento de um exercício crítico, sem concessões, a todo candidato à verdade, permitindo entrever a direção de sua condução por uma instância crítica, o Supereu.

Um trabalho recente de Manzi Filho (2017) aborda as meditações cartesianas a partir de sua dimensão melancólica, partindo de um parecer "contraintuitivo" da filósofa Olgária Matos (1997, p. 105) sobre as meditações.

Mas à ordem dedutiva das razões, à sequência de cadeias e elos entre evidências (indicações do método cartesiano), mescla-se a apresentação do Discurso do método como um antimétodo; Descartes quer que seu leitor o tome como a "história de sua vida", dos caminhos e descaminhos que ele próprio palmilhou até alcançar uma Ideia irrefutável e indubitável - o pensamento - de onde se assegura para desenvolver a 
Ciência, agora, moderna. Uma "fábula", diz ele. Reflexões que se desenvolvem entre a ciência e a ficção, e que têm por objetivo ser um modelo de ação para quem se sentir sensibilizado por seu pensamento.

Certificando-se de não incorrer em um psicologismo, uma leitura laplanchiana das meditações pode ser pensada tendo em vista um ponto já identificado por Derrida e outros autores, a de que o discurso das meditações e moderno tem a loucura, pretensamente expulsa do pensamento, figura como um de seus pontos balizares. Além de constituírem um método, as Meditaçoes propriamente ditas e aquelas presentes no Discurso compõem uma reflexão pautada em uma experiência pessoal, fictícia ou não, em que percepções, afetos e idiossincrasias estão em causa nesse percurso conduzido pelo ideal da Razão. Sobre esse aspecto pessoal dessas meditações, Descartes (1637/1981, p. 40) diz que "O meu intento jamais foi além de procurar reformar meus pensamentos, e construir um terreno que é todo meu. De modo que, embora tenha minha obra me agradado bastante e eu vos mostro aqui o seu modelo, nem por isso quero aconselhar quem quer que seja a imitá-lo".

Já nas meditações, quando abre mão de sua moral provisória, o filósofo transmitira uma vívida preocupação de que não pudesse cumprir o fim de resgatar as crenças suspensas, ficando no meio do caminho, em um cenário de incômoda incerteza. Sobre isso, confessa:

$\mathrm{E}$, não diferentemente do prisioneiro que, desfrutando talvez de um sonho de liberdade imaginária, quando começa em seguida a desconfiar que está dormindo, teme despertar e, por prudência, passa a ser conveniente com doces ilusões, a fim de que o logrem por mais tempo, assim também eu volto a cair espontaneamente em minhas inveteradas opiniões, receio acordar de medo que a vigília laboriosa, que venha a suceder o sossegado repouso não transcorra de agora em diante, não sob alguma luz, no conhecimento da verdade, mas em meio às inextricáveis trevas das dificuldades que acabam de ser suscitadas. (Descartes 1641/2004, p. 23)

Além dessas confissões, nota-se que a condução de Descartes tem em causa sua experiência, a qual aplicara um método racional, fato que abre a possibilidade de interpretações psicológicas da obra (Loeb, 2009, p. 279). Uma leitura psicanalítica, orientada em Laplanche, contudo, não necessita levantar a dimensão da percepção e experiência contida nas meditações, bastando apenas certificar de que a obra foi escrita por um sujeito. Ou seja, que a obra figura como recurso de simbolização, tradutivo de uma experiência, seja ela fictícia ou não.

Laplanche, na trilha de Freud, aborda o recalque originário como primeira divisão do aparelho psíquico, surgindo o inconsciente como resto tradutivo das mensagens parentais (Tarelho, 2012, p. 103). Para Laplanche (1992, p. 139), “o ser humano é e não para de ser autotradutivo e autoteorizante. O recalcamento originário é apenas o momento primeiro e fundante de um processo que dura a vida toda”. Para o autor, o recalcamento é situado segundo um modelo tradutivo, no qual o objeto fonte permanece não traduzido e atraindo o resto de outras traduções. 
Assim, traduzir e simbolizar apresentam um vínculo mais estreito com o recalque do que se pode aventar em Freud.

Paul Valéry tece um breve comentário sobre o movimento de Descartes nas meditações, indo ao encontro do que já fora abordado aqui.

O caso de Descartes, porém, talvez seja o mais estranho que se possa imaginar. Voltemos aos acontecimentos de 10 de novembro de 1619. Foram Eles precedidos por um período de atenção e de excitação intensa, durante o qual a luz e a certeza se declararam e o projeto maravilhoso (mirabilis scientae fundamenta) deslumbrou seu autor (1975, p. 8).

Nesse trecho, é descrita a trajetória de um estado tensivo à descoberta de um projeto, um sentido, cujos efeitos podem ser tidos como catárticos. Convém observar aqui que Descartes tivera, nesse episódio descrito por Valéry, três sonhos (Strathern, 1997, p. 21), cuja discussão não cabe aqui, tendo lugar apenas dizer que destes o filósofo extraiu um sentido: a revelação da vocação que recebera de Deus. Chama a atenção dos estudiosos o modo como Descartes retirara uma nobre e triunfante vocação das visões aterradoras contidas em seus sonhos.

Os acontecimentos descritos por Valéry figuram como prólogo do que veio a suceder nas Meditações e Discurso do Método. Inicialmente, Descartes apresenta seus objetivos e método intercalados por uma descrição narrativa de eventos pessoais, com a predominância da primeira pessoa. Nesse primeiro ponto, torna-se clara e acessível ao leitor a proposta de reforma dos próprios pensamentos (Descartes
1637/1981, p. 40), bem como o recurso da dúvida metódica, expresso no Discurso em termos de duvidar de tudo aquilo que fosse apenas verossímil (Descartes 1637/1981, p. 36).

O primeiro parágrafo da Primeira Meditação (Descartes 1641/2004, p. 23), bem como o seguinte trecho do Discurso fazem transparecer, para além do propósito metodológico de Descartes, uma insatisfação com o atual estado de organização de seus pensamentos, especificamente com a confiabilidade que poderia atribuir a eles. Assim, Descartes expressa incômodo com a limitação tradutiva das representações de que dispõe, cujos efeitos reconhecidos engajam-no na desconstrução da primeira em busca de simbolizações que tornassem sua experiência menos tensiva.

A verdade é que, ao limitar-me a observar os costumes dos outros homens, pouco encontrava que me satisfizesse, pois percebia neles quase tanta diversidade como a que notara anteriormente entre as opiniões dos filósofos. De forma que o maior proveito que daí tirei foi que, vendo uma quantidade de coisas que, apesar de nos parecerem muito extravagantes e ridículas, são comumente recebidas e aprovadas por outros grandes povos, aprendi a não acreditar com demasiada convicção em nada do que me havia sido inculcado só pelo exemplo e pelo hábito; e, dessa maneira, pouco a pouco, livrei-me de muitos enganos que ofuscam a nossa razão e nos tornar menos capazes de ouvir a razão (Descartes, $1637 / 1981$, p. 36) 
Assim, nota-se que o expresso propósito metodológico de Descartes mantém insuspeito um objetivo não declarado, bastante próximo do objetivo geral de uma análise: produzir formas menos sofríveis de se viver (Carvalho, 2006). Aventurando-se no ato que recomendava aos seus pares filósofos (Cottingham, 2009, p. 12), Descartes acaba por promover em seu exercício cético a destituição de um conjunto de simbolizações tradutoras de sua experiência, rejeitando a crença nestas. Como consequência, temos a suspensão de seu efeito protetor em relação ao recalcado, que faz emergir um excesso pulsional, sentido no corpo e que o engenho tem dificuldades em simbolizar e comunicar.

A desordem de tais sensações se aproxima daquilo que Descartes vivenciara em seus três sonhos aterradores, com a diferença de que nas Meditações, a emergência do recalcado dáse pela rejeição provisória de um complexo tradutivo e, no caso dos sonhos, ocorre em função do rebaixamento da atividade censora no evento do sono. Nas Meditaçoes ocorre a repetição da abertura ocorrida na noite dos três sonhos.

A referida abertura corresponde à suspensão de um pseudodomínio correspondente ao modelo ptolomaico (Laplanche, 1998 p. 89), não só reputado, como buscado enquanto centro e origem. Essa suspensão corresponde ao deslocamento copernicano que caracteriza a situação analítica. Descartes orbita inicialmente em torno de si mesmo, enquanto dotado de equívocos e preconceitos, e, posteriormente, em torno do Gênio Maligno, figura alteritária que encarna a dimensão disruptiva do Supereu. Se, por um lado, o Supereu é reconhecido como herdeiro do complexo de Édipo, por outro, encerra em si a dimensão da pulsão de morte (Nakasu, 2012, p. 468), derivada dos excessos pulsionais que se impõem ao primeiro humano na ocasião dos primeiros cuidados.

$\mathrm{Na}$ chamada situação fundamental, a criança está completamente sujeita ao adulto cuidador. Em função dessa assimetria, e à revelia da intenção do cuidador, são emitidas mensagens enigmáticas que se pretendem autoconservativas.

Aquilo que denominamos "mensagens enigmáticas", são mensagens dirigidas do adulto para a criança, mensagens que pretenderiam ser puramente de autoconservação: quero te alimentar, quero te cuidar, etc., mas que constituem uma "conciliação" (no sentido freudiano do termo) pela mistura de fantasias sexuais. Eu te alimento, porém inconscientemente - eu te enfio o alimento no sentido sexual da intromissão (a Nabrungsafubr se torna Nahrungseinfubr - como aparece em um significativo lapso de Freud no seu Projeto). (Laplanche, 1998, p. 89)

O gênio maligno apresenta-se como figura de uma alteridade caprichosa e um dos principais impedimentos para o movimento de recentramento das meditações, uma vez que se está completamente sujeito a suas ações. Tal figura da alteridade guarda vínculo com a dimensão fantasmática do adulto cuidador, cujas mensagens jamais são completamente traduzidas. Nessa situação primária, a insuficiência da função simbolizadora e prematuridade do pequeno humano assentam o fundamento alteritário e 
copernicano da condição humana, condicionada por seu desamparo inicial.

Contudo, o movimento de abertura é revertido com a conclusão de seu Cogito, quando ao duvidar é pressuposto um eu que pensa tais dúvidas. Esse ponto de corte marca $\mathrm{O}$ deslocamento da referência interna alteritária, do Supereu caprichoso, para o campo ptolomaico do eu, movimento que é sucedido pelo recurso à perfeição de Deus para restabelecer as crenças anteriormente rechaçadas. Nota-se um claro contraste entre a figura do Gênio Perverso e o Deus perfeito, duas figuras alteritárias que balizam a meditações, sendo o último referência para centralização do eu em sua constelação psíquica. Trata-se aqui de uma "tradução da tradução" (Laplanche, 1998, p. 93) contida no percurso metodológico das meditações, cujo conteúdo final é melhor integrado aos interesses do Eu, propiciando o fechamento da abertura ocorrida no início das meditações.

Por fim, é interessante constatar e reversibilidade de movimentos ptolomaicos e copernicanos, ou seja, de abertura e fechamento no percurso das meditações. Tal aspecto pode ser melhor abordado tendo em vista a explicação freudiana sobre a reversibilidade do recalque em A Gradiva de Jensen

Esses casos comprovam o velho ditado latino: "Naturam expelles furca, tamem usque recurret", embora este originalmente se referisse somente à expulsão por influências externas, e não por conflitos internos. No entanto, esse provérbio não nos explica tudo; só nos informa sobre o fato do retorno da parte da natureza que foi reprimida, mas não descreve a maneira altamente singular desse retorno, que se realiza através do que classificaríamos de malévola traição. É precisamente o que foi escolhido como instrumento da repressão - como o "furca" do provérbio latino - que vai constituir o veículo do retorno: oculto na força repressora, o que é reprimido revelar-se-á por fim vencedor. (Freud, 1907[1906]/1996, p. 40)

$\mathrm{O}$ projeto das meditações, associado à revelação decorrente de três sonhos aterradores e com a expressa finalidade de organizar seus pensamentos, levou Descartes a expressar atemorização em certa medida de seu percurso. Do mesmo modo, a partir da dúvida hiperbólica, aprofundamento radical dessa experiência disruptiva é que o filósofo reverte a abertura em um recentramento. Tal fato é demonstrativo do modo como o processo tradutivo é uma exigência de trabalho imposta pelo pulsional implantado e constitutivo. Tal se afigura o conflito, entre eu e outro interno, no qual o copernicanismo, como podemos observar nas meditações, ao fim do desenvolvimento de uma abertura, recua para o restabelecimento dessa falsa centralidade do eu que resguarda a vida.

\section{Considerações finais}

Laplanche (1998, p. 93) propõe que uma análise recoloque em jogo o "conflito copernicano originário" por meio de duas vias: a) da situação analítica e da transferência que nela se produz e b) a análise, como método de destradução. Esse segundo movimento pode ser observado nas meditações de Descartes quando 
coloca em suspensão suas crenças até então admitidas sob uma justificativa revisionista e metodológica. Contudo, Esse cálculo não deixa de levá-lo a expressar certo temor, já que seu procedimento suspendera o efeito defensivo da rede de traduções em que consistia o conjunto de suas crenças. Tal abertura tem na figura do gênio maligno, perverso ou enganador a manifestação de uma alteridade interna, cuja radicalidade propiciou o fechamento dessa mesma abertura. Há assim, em Descartes, um precursor metódico das experiências almejadas na situação analítica.

\section{Referências}

Birman, J. (2010). Descartes, Freud e a experiência da loucura. Natureza bumana, 12(2), 5-21.

Campos, E. B. V. (2012). Os fundamentos da Constituição Subjetiva segundo Laplanche. Impulso, 22(55), 21-34.

Carvalho, A. C. (2006). O ofício do psicanalista. Percurso, Revista de Psicanálise, 17-26.

Conttingham, J. (2009) Introdução. In J. Conttingham (Org.). Descartes (A. Oídes, Trad., pp. 11-32). Aparecida, SP: Ideias e Letras.

Damasio, F. (2011). O início da Revolução Científica: questões acerca de Copérnico e os epiciclos, Kepler e as órbitas elípticas. Revista Brasileira de Ensino de Física, 33(3), 1-6.

Descartes, R. (1981). Discurso do método (E. Marcelina, Trad.) Brasília: Editora
Universidade de Brasília; São Paulo: Editora Ática. (Original publicado em 1637).

Descartes, R. (2004). Meditações sobre Filosofia Primeira. - Ed. Bilíngue em latim e português (F. Castilho, Trad.) Campinas: Editora da Unicamp. (Original publicado em 1641).

Debus, A. G. (2004). Ciência e História: o nascimento de uma nova área. In A. M. Alfonso-Goldfarb M. H. R. \& Beltran (Orgs). Escrevendo a História da Ciência: tendências, propostas e discussões historiográficas (pp. 13-39). São Paulo: EDUC/Livraria Editora da Física/Fapesp.

Dostoiévski, F. M. (2008). Os irmãos Karamázov (P. Bezerra, Trad., Vol. I, pp. 13-14). São Paulo: Editora 34.

Freud, S., \& Breuer, J. (1976). Estudos sobre histeria (1893-1895). (J. Salomão, Trad.) Edição Standard Brasileira das Obras Completas Psicológicas de Sigmund Freud. Rio de Janeiro: Imago. (Trabalho original publicado em 1895).

Freud, S. (1986). A correspondência completa de Sigmund Freud para Wilhelm Fliess (V. Ribeiro, Trad.). Rio de Janeiro: Imago. (Correspondências originais enviadas entre 1887 e 1904).

Freud, S. (1990). Conferência XIX Resistência e Repressão. In J. Strachey (Ed., J. Salomão, Trad.). Edição Standard brasileira das obras psicológicas completas de Sigmund Freud. Rio de 
Janeiro: Imago. (Original publicado em 1917).

Freud, S. (1996). "Gradiva" de Jensen (19061908). In "Gradiva" de Jensen e outros trabalhos (J. Salomão, Trad., pp. 15-87). Edição Standard Brasileira das Obras Completas Psicológicas de Sigmund Freud. Rio de Janeiro: Imago. (Original publicado em 1907[1906]).

Freud, S. (1996). Projeto para uma Psicologia Científica. In Publicações PréPsicanalíticas e Esboços Inéditos - 18861889 (J. Salomão, Trad., pp. 335-469). Edição Standard Brasileira das Obras Completas Psicológicas de Sigmund Freud. Rio de Janeiro: Imago. (Original publicado em 1950).

Freud, S. (2006). Além do princípio de prazer, Psicologia de Grupo e outros trabalhos 1920-1922 (J. Salomão, Trad.). Edição Standard Brasileira das Obras Completas Psicológicas de Sigmund Freud. Rio de Janeiro: Imago. (Trabalhos originais publicados entre 1920 e 1922).

Honda, H. 2013. O estatuto conceitual do inconsciente em Freud e algumas de suas implicações para a prática psicanalítica. Ágora, 16 (edição especial), 41-57.

Lacan, J. (1980). Carta de Dissolução. Rev. Letra Freudiana, $I(0)$, 45, e na "Ata de Fundação da E. F. P”, 1964, p. 17.

Laplanche, J. (1988). Da Teoria da Sedução Restrita à Sedução Generalizada. In Teoria da Sedução Generalizada e outros ensaios (D.
Vasconcellos, Trad., pp. 108-125). Porto Alegre: Artes Médicas.

Laplanche, J. (1992). Novos Fundamentos para a Psicanálise (C. Berliner, Trad.). São Paulo: Martins Fontes. (Original publicado em 1987).

Laplanche, J. (1993). A Revolução Copernicana Inacabada. Projeto Revista de Psicanálise, 3(4).

Laplanche, J. (1997). Freud e a sexualidade: o desvio biologizante (L. Magalhães, Trad.). Rio de Janeiro: Jorge Zahar. (Original publicado em 1993).

Loeb, L. E. (2009). O círculo cartesiano. In J. Conttingham (Org.). Descartes (A. Oídes, Trad., pp. 243-284). Aparecida, SP: Ideias e Letras.

Matos, O. C. (1997). Filosofia, a polifonia da razão: filosofia e educação. São Paulo: Scipione.

Manzi Filho, R. (2017). O robe de Descartes: uma discussão em torno da melancolia e da origem da razão moderna. Princípios: Revista de Filosofia, 24(43), 81-106.

Miller, J. A. (2004). O percurso de Lacan: uma introdução (A. Roitman, Trad.). Rio de Janeiro: Jorge Zahar Editor. (Original publicado em 1984).

Nascimento, E. (2017). O debate Foucault e Derrida: razões ou desrazões do pensamento. Matraga-Revista do Programa de Pós-Graduação em Letras da UERJ, 24(40), 135-153. 
Nakasu, M. V. P. (2012). Avatares da instância crítica: supereu entre o isso e o princípio de morte. Psicologia USP, 23(3), 467-480.

Porto, C. M., \& Porto, M. B. D. S. M.. (2008). A evolução do pensamento cosmológico e o nascimento da ciência moderna. Revista Brasileira de Ensino de Física, 30(4), 4601.14601.9.

Rondon, P. H. B. (1998). Tradução: Objetivos do processo psicanalítico. Cadernos de Psicanálise SPCRJ, 14(17), 79-101.

Strathern, P. (1997). Descartes em 90 minutos (M. H. Geordane, Trad.). Rio de Janeiro: Zahar.

Tarelho, L. C. (2012). A teoria da sedução generalizada de Jean Laplanche e o descentramento do ser humano. Jornal de Psicanálise, 45(83), 97-107.

Teixeira, A. M., \& J. Santiago (2017). Semiologia da percepção: o enquadre da realidade que retorna no real. In A. M. Teixeira \& H. Caldas (Orgs). Psicopatologia lacaniana (pp. 93-121). Belo Horizonte: Autêntica.

Valéry, P. (1975). O pensamento vivo de Descartes. Apresentado por Paul Valéry (M. de L. Teixeira, Trad.). São Paulo: Livraria Martins Editora. (Original publicado em 1965).

Recebido em: 23/5/2018

Aprovado em: 23/6/2018 